\title{
Planned Parenthood: Supply Induced Demand for Abortion in the US
}

\author{
James Studnicki*, John W. Fisher \\ Charlotte Lozier Institute, Arlington, VA, USA \\ Email: *jstudnicki@lozierinstitute.org
}

How to cite this paper: Studnicki, J. and Fisher, J.W. (2018) Planned Parenthood: Supply Induced Demand for Abortion in the US. Open Journal of Preventive Medicine, 8, 142-145. https://doi.org/10.4236/ojpm.2018.84014

Received: March 28, 2018

Accepted: April 25, 2018

Published: April 28, 2018

Copyright $\odot 2018$ by authors and Scientific Research Publishing Inc. This work is licensed under the Creative Commons Attribution International License (CC BY 4.0).

http://creativecommons.org/licenses/by/4.0/

\section{(c) (i) Open Access}

\begin{abstract}
The rate and number of induced abortions in the US has declined steadily for nearly three decades. In contrast to this overall reduction, Planned Parenthood Federation of America abortion providers exhibit a persistent increase in both abortions and their market share percentage of total abortion procedures. For the period 1995-2014, estimated annual and cumulative excess abortions are calculated (Planned Parenthood Abortion Inflation Effect-PPAIE) to indicate the number of abortions which would have been averted if the PP utilization experience had been identical to that of Non-PP abortion providers. PP excess abortions grew steadily each year from 21,000 in 1996 to 258,200 in $2014,28 \%$ of total abortions that year. The cumulative number of abortions added by the PPAIE from $1995-2014$ was $3,025,560$ or $12.5 \%$ of the $24,112,600$ performed. Planned Parenthood has had a long-term and accelerating inflationary effect on the incidence and prevalence of abortion in the US.
\end{abstract}

\section{Keywords}

Abortion, Supply Induced Demand (SID), Reproductive Health Policy, Planned Parenthood

\section{Introduction}

Providers can use their discretionary power to engage in demand inducement activities which can alter the volume of services delivered [1] [2] [3]. Supply sensitive services are likely to be discretionary in nature; i.e. those for which there is a wide range of choice as to whether or not the service is provided [4]. One important indication of extant supply induced demand (SID) is high small area variation rates for the service [5]. Expressed as the number of abortions per 1000 women age $15-44$, in 2014, there was a 26 -fold difference between the states with the highest (New York, 29.6) and the lowest (Wyoming, 1.1) abortion rates 
[6]. There is, in addition, a remarkable supply related paradox which is suggestive of the influence of SID. While the number and rate of abortions in the US has consistently declined for nearly three decades, Planned Parenthood (PP) abortion providers have maintained an equally consistent, but starkly contrarian, pattern of rising abortion utilization.

\section{Methods}

We extracted data from two major sources for every statistic in these analyses: 1) Planned Parenthood Federation of America (PPFA) annual reports, 1995-2014; and 2) The Guttmacher Institute, reports of abortion rates and volumes, 1973-2014.

Annual abortions are segmented into those provided by PP and non-Planned Parenthood (Non-PP) providers. With 1995 as the reference year, year-to-year and cumulative rate differences between the two groups are specified. Estimated annual and cumulative excess abortions are calculated to indicate the number of abortions which would have been averted if the PP utilization experience had been identical to that of the Non-PP providers. We refer to this estimation of excess abortions as the Planned Parenthood Abortion Inflation Effect (PPAIE).

\section{Results}

Between 1973 and 1980, US abortions more than doubled to 1,553,890. For the next decade, the number stabilized between 1.5 - 1.6 million, peaking at 1,608,600 in 1990. From that high, the number and rate of abortions began a steady decline which has lasted nearly 30 years.

During the 20 years 1995-2014, the number of abortions decreased $31 \%$ from $1,359,400$ to 926,200 and the abortion rate decreased $35.1 \%$ from 22.5 to 14.6 .

Non-PP abortions reflect the national trend during the period, decreasing $50.8 \%$ from $1,225,500$ to 602,200 . PP abortions, by contrast, increased $142 \%$ from 133,900 to 324,000 . The resultant PP market share increased from $10 \%$ in 1995 to $35 \%$ in 2014 (Figure 1).

The number of excess abortions resulting from the PPAIE grew steadily each year because of the opposite and diverging trends of the two groups over the 20 year period. PP excess abortions were just over 21,000 in 1996 and had grown to 258,200 in 2014 , nearly $28 \%$ of total abortions that year. The cumulative number of abortions added by the PPAIE from 1995-2014 was 3,025,560, $12.5 \%$ of the total of 24,112,600 performed (Figure 2).

\section{Discussion}

SID may be motivated by financial gain for the service providers, by patients who are not fully informed of their options and thus delegate the decision to the supplier, and by the influence of provider values [1].

Despite a 25\% reduction of total unduplicated clients between $1995(3,334,203)$ and $2014(2,500,000)$, PP revenues from government reimbursement and grants 


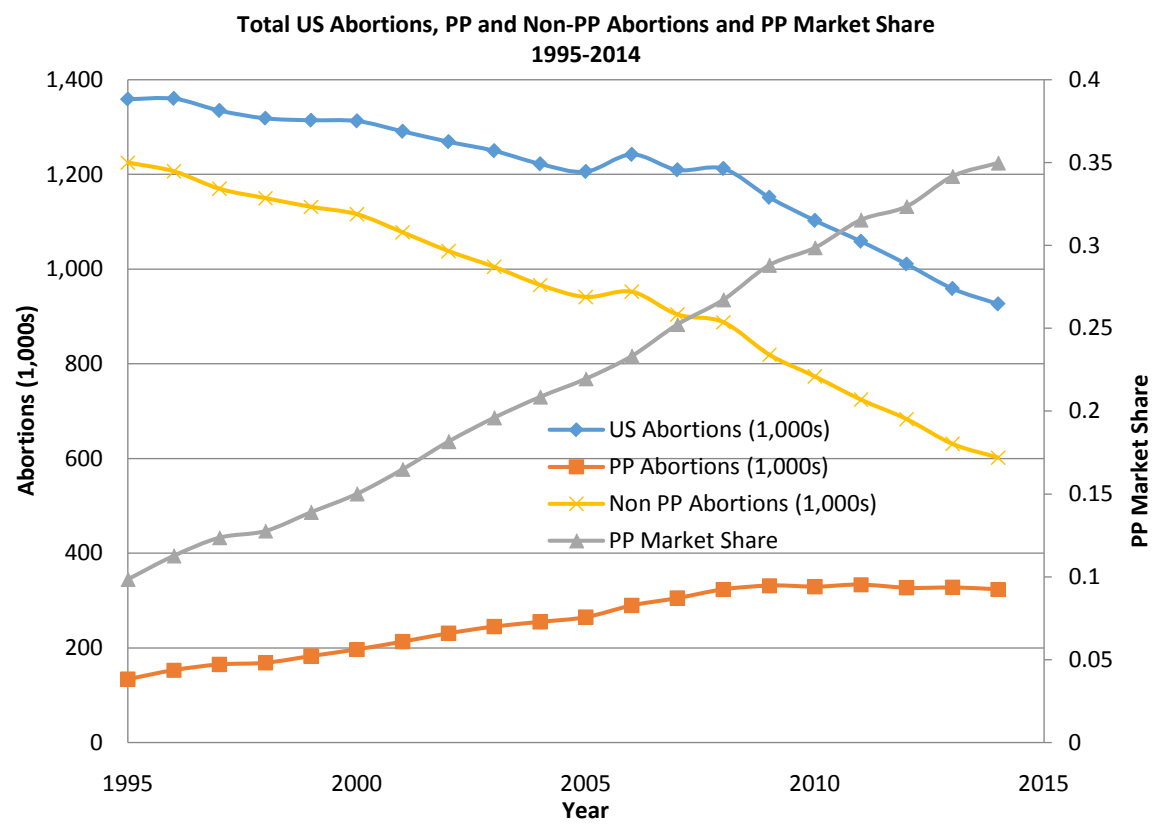

Figure 1. Abortion trends 1995-2014.

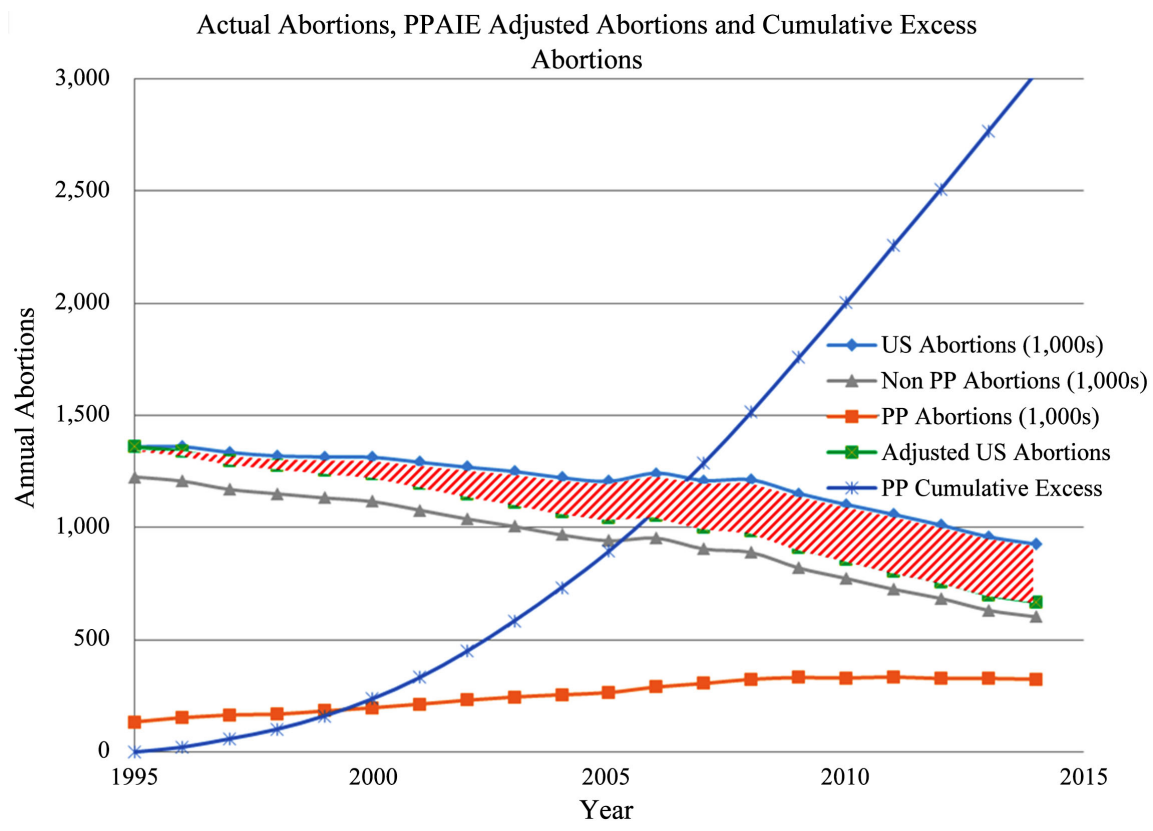

Figure 2. Estimated excess abortions 1995-2014.

increased $220 \%$ from $\$ 112$ million to $\$ 554$ million, reflecting a shift from low-revenue counseling and contraception services to much higher revenue abortions. Similarly, total net assets during the period increased nearly $400 \%$ from $\$ 310$ million to $\$ 1.5$ billion, indicative of a service with a higher profitability mix. PP eschews information on abortion options such as adoption referrals, and provides no post-natal care. Finally, it would be difficult to exaggerate the promotional impact of the coalescence of PP with a national political party and their mutual embrace of pro-abortion ideology and values. The evidence sug- 
gests that PP has had a long-term inflationary effect on the incidence and prevalence of abortion in the US.

Abortion is usually provided on demand in the US, and without the application of rigorous standards of medical necessity and appropriateness which serve as the means to measure and, if necessary, restrain the overuse of legitimate medical services. Coupled with the absence of a national abortion certification and reporting system, this lack of utilization oversight enables unfettered supply induced demand by an entire class of abortion providers.

\section{References}

[1] Bickerdyke, I., Dolamore, R., Monday, I. and Preston, R. (2002) Supplier Induced Demand for Medical Services. Productivity Commission Staff Working Paper, Canberra.

[2] Reinhardt, U.E. (1985) The Theory of Physician Induced Demand: Reflections after a Decade. Journal of Health Economics, 4, 187-193. https://doi.org/10.1016/0167-6296(85)90008-6

[3] Shigeoka, H. and Fushima, K. (2014) Supplier-Induced Demand for Newborn Treatment: Evidence from Japan. Journal of Health Economics, 35, 162-178. https://doi.org/10.1016/j.jhealeco.2014.03.003

[4] Sirovich, B., Gallagher, P.M., Wennberg, D.E. and Fisher, E.S. (2008) Discretionary Decision Making by Primary Care Physicians and the Cost of U.S. Health Care. Health Affairs, 27, 813-823. https://doi.org/10.1377/hlthaff.27.3.813

[5] Wennberg, J., McPherson, K. and Goodman, D. (2016) Small Area Analysis and the Challenge of Practice Variation. In: Johnson, A. and Stukel, T., Eds., Medical Practice Variations, Springer, New York, 1-24. https://doi.org/10.1007/978-1-4899-7603-1_65

[6] Jones, R.K. and Jerman, J. (2017) Abortion Incidence and Service Availability in the United States, 2014. Perspectives on Sexual and Reproductive Health, 49, 17-27.

https://doi.org/10.1363/psrh.12015 